\title{
Umbrales, remediaciones y cultura material en la poesía venezolana contemporánea
}

\author{
Thresholds, Remediations, and Material Culture \\ in Contemporary Venezuelan Poetry \\ Umbrais, remediações e cultura material na \\ poesia venezuelana contemporânea
}

\section{Miguel Gomes}

THE UNIVERSITY OF CONNECTICUT, ESTADOS UNIDOS

Profesor de Literatura Latinoamericana en The University of Connecticut,

Estados Unidos. Doctor en Literaturas Hispánicas, Stony Brook

University, Estados Unidos. Autor de La realidad y el valor

estético: configuraciones del poder en el ensayo hispanoamericano

(Equinoccio/Universidad Simón Bolívar, 2010), Poéticas del ensayo venezolano del siglo $X X$ (Universidad del Zulia/Universidad Cecilio

Acosta, 2008), Los géneros literarios en Hispanoamérica: teoría e historia (Ediciones de la Universidad de Navarra, 1999). Editor de Estética hispanoamericana del siglo XIX (Biblioteca Ayacucho, 2003) y Estética del modernismo hispanoamericano (Biblioteca Ayacucho, 2002). Correo electrónico: miguel.gomes@uconn.edu 


\section{Resumen}

La llegada del siglo XXI ha coincidido con profundas transformaciones del campo de producción cultural venezolano, aceleradas desde 2001 por el anuncio presidencial de una "revolución cultural", cuyas pugnas simbólicas han acompañado el progresivo enrarecimiento de la vida nacional. No solo el campo cultural se fracciona en dos círculos -el oficial y el opositor-, sino que en ciertos autores se observa una radical experimentación con nuevos lenguajes y tecnologías en los que se expresa un proyecto de intervención social. El presente trabajo contextualiza y describe algunas variables de esa experimentación en la lírica.

Palabras clave: poesía venezolana; cultura material; Hugo Chávez; Blanca Strepponi; Igor Barreto; Willy McKey

\section{Abstract}

The Venezuelan field of cultural production has undergone numerous transformations in the twenty first century, especially since Hugo Chávez announced in 2001 the need for a "cultural revolution." As a result, many symbolic struggles have accompanied the constant political tensions in which the country has been immersed. Not only the field of cultural production has become divided into two opposing subfields-those who subscribe to the official policies and those against them, but also several authors have developed an interest in expressing their social views through a radical experimentation with new languages and technologies. This article describes and contextualizes a few instances of such experiments among contemporary poets.

Keywords: Venezuelan poetry; material culture; Hugo Chávez; Blanca Strepponi; Igor Barreto; Willy McKey

\section{Resumo}

A chegada do século XXI coincidiu com profundas transformações do campo de produção cultural venezuelano, aceleradas desde 2001 pelo anúncio presidencial de uma "revolução cultural", cujas pugnas simbólicas já acompanharam o progressivo enrarecimento da vida nacional Não apenas o campo cultural é fracionado em dois círculos $\square_{0}$ oficial e o opositor $\square$, senão que em certos autores observa-se uma experimentação radical com novas linguagens e tecnologias nos que se expressa um projeto de intervenção social. $\mathrm{O}$ presente trabalho contextualiza e descreve algumas variáveis dessa experimentação na lírica.

Palavras-chave: poesia venezuelana; cultura material; Hugo Chávez; Blanca Strepponi; Igor Barreto; Willy McKey

RECIBIDO: 11 DE OCTUBRE DE 2015. ACEPTADO: 20 DE NOVIEMBRE DE 2015. DISPONIBLE EN LÍNEA: 1 DE JULIO DE 2016

Cómo citar este artículo:

Gomes, Miguel. "Umbrales, remediaciones y cultura material en la poesía venezolana contemporánea". Cuadernos de Literatura 20.40 (2016): 410-429. http://dx.doi.org/10.11144/Javeriana.cl20-40.urcm 
LA L LE G A D A D E siglo XXI será recordada como época de profundas transformaciones en la literatura venezolana, aceleradas desde 2001 a raíz del anuncio oficial de una "revolución cultural" sentida por muchos como "declaración de guerra" (Torres, El oficio 245). Entre los cambios producidos, me limito a destacar el afianzamiento de lo que Sandra Pinardi llama régimen político, en el que las obras de arte se vuelven "puntos de inflexión que vinculan disímiles territorios de la trama cultural", fenómeno irreductible al activismo de los "compromisos" de otras épocas, ya que arraiga de manera honda en las formas y los medios (107). Pese al nombre, lo descrito por Pinardi coincide con el "régimen estético" que, según Jacques Rancière, despuntó en el seno del romanticismo alemán, con una comunión de praxis social y artística, así como con el rechazo de experiencias que disgreguen ambos dominios (40).

Comoquiera que denominemos ese régimen, lo cierto es que la pérdida de autonomía del campo cultural venezolano, sugerida por algunos críticos en vista de la vocación política de los autores, ${ }^{1}$ quizá no se verifique si reparamos en que las leyes autonómicas no han imperado siempre en el arte de numerosos países latinoamericanos o, al menos, no han funcionado igual que en Europa. Por la génesis del campo en circunstancias poscoloniales y su ideal de hacer nación, uno de los criterios persistentes para acumular capital simbólico en Venezuela ha sido paradójicamente el carácter ancilar de la obra respecto a las fuentes del poder. Dicho carácter genera la intuición perenne de que la autonomía — de haberla- es más bien frágil.

Pospolítica y postautonomía, términos que ha usado la crítica (Vargas Álvarez; Ludmer), en todo caso, no me parecen trasladables indiscriminadamente a Venezuela, porque encarnan una utopía letrada a la que puede aplicarse lo dicho por Žižek sobre la ideología: "la era contemporánea se proclama postideo, pero su negación de la ideología solo nos proporciona la prueba definitiva de que estamos más sumergidos que nunca en esta" (37; traducción del autor). Sospecho que ello lo corrobora lo que ha venido pasando en un género como la lírica desde 1989, año en que se inauguró una serie de acontecimientos violentos - que incluyen saqueos, matanzas e intentos de golpe de Estado- indicadores del fin del aire próspero y democrático que había tenido el país. Lo que primero llama la atención al que se enfrenta a dicho panorama es una alteración de los tratos de la poesía con el entorno de la cultura material, pues justo por esos años comienza

1 Pienso en Pedro Luis Vargas Álvarez, en un artículo muy atendible desde otros puntos de vista. Lo que sostiene sobre la "pospolítica" de la novela histórica comercializada durante el periodo que examina, por ejemplo, me parece correcto, aunque no proyectable a otros géneros. 
a volverse frecuente en toda manifestación artística lo que Marjorie Perloff, en otros contextos, ha designado como videación (videation, 74): el influjo de una visualidad no solo proveniente de la plástica, la fotografía o el cine, sino también de la televisión y los medios de comunicación de masas en general. La videación, en los albores del siglo XXI, dará paso en la poesía venezolana a la remediación - acudo ahora a otro término necesario, empleado por Jay David Bolter y Richard Grusin en su libro Remediation: Understanding New Media- en la que encontraremos textualidades traspasadas por lo digital.

Lo anterior sucede, sin embargo, y aquí planteo una pieza fundamental de mi argumento, no por mera fascinación formalista, sino por una urgencia experimental que responde al horizonte político. Se publican obras doblemente codificadas: por una parte, atractivas para el consumidor curioso ante las aparentes extravagancias y el elemento de espectáculo; por otra, atractivas para círculos intelectuales gracias a los riesgos de lenguaje y la crítica latente en esas conductas semióticas. La consecuencia es una apertura de lo cultural a las demás zonas sociales y un potenciamiento de sus fuerzas autonómicas, solo posible, como sostuvo Bourdieu, cuando lo elitista se reinvierte simbólicamente para sustentar intervenciones en el macrocampo del poder (459). Lo que señalo en varios títulos recientes de la poesía venezolana, en efecto, los aleja del tecnonarcisismo. María Antonieta Flores, autora destacada, apunta sin equívocos la razón: debido a la mella que hacen en el ánimo del escritor venezolano las escisiones de los años recientes, se han vuelto constantes "el uso de redes sociales, las publicaciones digitales, la sobreexposición como actos para probar la existencia: hay en ello un horror a ser silenciados" (174). Consecuencia de la desaparición de las usuales vías previas de publicación, la adopción de múltiples medios y tecnologías sirve así como táctica en un programa de lucha en el terreno simbólico contra discursos autoritarios y monológicos. ${ }^{2}$

Para comprender mejor la índole pluralista de la poesía que estudio, puntualizo en qué consiste ese autoritarismo. La manera más sintética es releer declaraciones del ideario estatal firmadas por Hugo Chávez, cuya doctrina resulta a todas luces neocaudillista, con una visión decimonónica y bélica del hecho

2 Las editoriales estatales habían acogido a poetas de cualquier orientación política en los años setenta y ochenta, situación que se altera a partir de 1999, cuando la exclusión o la autoexclusión obliga a explorar nuevos canales de circulación de los textos. Si bien la narrativa de autores de oposición halló un asilo hasta entonces inesperado en las firmas transnacionales que operaban en el país -Alfaguara, Random House Mondadori, Seix Barral, por ejemplo-, la lírica se encontró mucho más desamparada y acaso su tendencia experimentalista tenga allí uno de sus orígenes. 
social cimentada en la ilusión de identidad entre la Independencia y las políticas actuales. En un discurso sobre la reforma constitucional de 1999, proclamaba, por ejemplo: "Hoy muere la Cuarta República y se levanta la República Bolivariana. Del Padre de la Patria viene esa revolución" (26). La delatora anfibología que subrayo aúna la guerra fundadora y el chavismo, confundidos sus líderes por iniciativa verbal del enunciante, cosa que la imagen del mandatario acompañada de retratos de Bolívar, circulante en la prensa oficial, siempre recalcó. Las columnas de prensa del entonces presidente bastarían asimismo para dar idea de sus hábitos elocutivos:

Soy, en esencia, un soldado [...]. Digo esto hoy, en medio de los acontecimientos que marcan el inicio de este 2009, cuando recrudece la batalla política que se desató en nuestra patria hace dos siglos: unos queremos la Independencia Nacional; otros, los menos, quieren convertir de nuevo a Venezuela en una colonia [...]. Nosotros, los Patriotas, tenemos un proyecto, portamos una bandera... Ellos, los colonialistas, no tienen juramento, no tienen proyecto, no tienen bandera. $\mathrm{O}$ mejor dicho, como lo hemos visto en diversas actividades de los pitiyanquis, su bandera al revés, volteada, de siete estrellas y no de ocho como fue el mandato de nuestro Bolívar en Angostura, lo dice todo: representan lo contrario a la patria, son la contrabandera, son la contravenezuela, son lo contrabolívar. Son la negación. Son la no-patria. (Chávez Frías, "Discurso" 5-8)

La retórica dual y mesiánica surgida de las esferas del poder, con su proceso caracterizado como "bolivariano", cambio oficial del nombre del país y otras operaciones similares, es decir, los esfuerzos alegóricos del chavismo que se remontan a orígenes heroicos patrios con una modernidad-oxímoron, estática, en que se gesta sempiternamente la nación, no son accidentales. Quien mejor ha descrito sus implicaciones para la psicología colectiva venezolana es la psiquiatra Ana Teresa Torres en un estudio que titula La herencia de la tribu. La llamada revolución bolivariana, señala, constituye una "alegoría melancólica de la Independencia" que predispone a quienes sienten sus efectos a descifrar el presente en términos de un pasado fundacional con correspondencias entre "padres" de la nacionalidad y Chávez (165190). El dialogismo de la poesía que examino a continuación requiere una calculada ambigüedad que dificulta el pensamiento dicotómico: allí estriba su propuesta ante los alegoremas polares y determinados del catecismo oficial.

Una poesía "remediada" puede ser política y sobran los ejemplos latinoamericanos, desde el concretismo brasileño a las experiencias chilenas de las décadas de los setenta y de los ochenta. Con todo, el precedente de lo que se hace 
en Venezuela lo encontraremos no en el exterior, sino en la tradición nacional. Se trata de las acciones interartísticas de El Techo de la Ballena. Ese fue el nombre que eligió un grupo de escritores y pintores, entre los cuales se cuentan figuras centrales de los años venideros - como Adriano González León, Salvador Garmendia, Carlos Contramaestre, Jacobo Borges y Caupolicán Ovalles-, quienes desarrollaron una rica actividad editorial conectada con exposiciones y quienes, en palabras de Ángel Rama, "confirieron su peculiar nota tumultuosa a la década del sesenta en Caracas, por su violencia y su espíritu anárquico [que hizo] de la provocación "un instrumento de investigación"” (12). Además de un deseo de reinsertar en Venezuela la dinámica de las vanguardias históricas, compartían un proyecto político de izquierda. A confesión de parte, una acción de arte realizada en 2010 por tres poetas jóvenes, Willy McKey, Santiago Acosta y Andrés González Camino - hijo de González León-, se inspira en una de las más famosas iniciativas de El Techo de la Ballena, titulada Homenaje a la necrofilia. Con motivo de una exposición de Contramaestre en 1962, los integrantes de El Techo desplegaron una campaña crítico-publicitaria que "llevó a cabo una de las primeras piezas performáticas venezolanas", cuya intención primordial era evidenciar "las muertes por la violencia política, tomando como materiales huesos y vísceras de animales y exhibiéndolos como gesto espinoso contra lo silenciado en los medios de comunicación" (McKey, Acosta y González, Necromenaje). Contramaestre, en efecto, buscó en mataderos los materiales de sus obras, lo que causó el escándalo necesario para que la Policía cerrara el Homenaje por motivos de higiene. Lo que McKey, Acosta y González Camino realizan en 2010 es un Necromenaje a la containerphilia y el blanco al que se apunta es la corrupción e incompetencia que permitió que se pudrieran toneladas de alimentos importados en las instalaciones de la red de distribución del Gobierno Bolivariano, la Productora y Distribuidora Venezolana de Alimentos (PDVAL) - dependiente de la petrolera del Estado-, caso que coloquialmente se conoce en Venezuela como Pudreval. La puesta al día del legado ballenero tuvo variantes formales importantes: en un espacio cuadrado con un área de cuarenta metros cuadrados se dispusieron en el suelo cien bandejas de 250 gramos de carne. A la izquierda, se proyectaba un texto que explicaba quién era Carlos Contramaestre y qué era El Techo de la Ballena. A la derecha había una silla de ruedas que perteneció a Alfredo Silva Estrada - poeta de obra muy intelectual y abstracta-, y dos patas de res que pendían de un nailon sobre los pies de la silla. Frente al texto proyectado había una cámara. Las personas que entraban debían leer ante ella un poema de Contramaestre, lo que les daba derecho a llevarse una bandeja de carne. Cada diez personas, se proyectaba la imagen de los recitantes encima de las bandejas. Esto 
hacía que la voz de aquellos grabados se colara en la de los nuevos recitantes, hasta que sumadas creaban un estruendo. Como explica McKey, los visitantes acababan "con una bandeja de carne gratis, pero sin saber bien qué hacer con ella" ("Carta").

Aparte de la videación y la remediación palpables, ha de acentuarse que la circunstancia del Necromenaje habría sido imprevista para los integrantes de El Techo de la Ballena, ya que el Gobierno de hoy se define estridentemente a sí mismo como izquierdista para poder encasillar todo amago de crítica como derechista. Lo más llamativo de la actualización que hacen McKey, Acosta y González Camino es la sugerencia de que en el fondo, nada, pese a la estridencia, se ha alterado: el malestar intelectual de la década de los sesenta, en pleno afianzamiento de un desarrollismo democrático, sigue vigente luego de doce años de una supuesta revolución cuyas exuberantes alocuciones proclaman el cambio. Revelador me parece ese desajuste de paradigmas en que se recurre a hechos de arte monumentalizados y desplazados a contextos políticos disímiles: la operación tiene la virtud de hacernos ver la inestabilidad de supuestas esencias polares. Izquierda y derecha, tanto como aquí o allá, son deícticos: palabras que poco significan fuera de situaciones enunciativas. Lo denunciado podría ser la preservación, camuflada con retórica "bolivariana", de los espejismos de la derrochadora Venezuela "saudita" de los años sesenta y setenta.

La trasposición de los proyectos poéticos a acciones que incorporan medios digitales en el Necromenaje es un último estadio de un proceso para nada sencillo. Sospecho que este podría rastrearse a lo largo del periodo de crisis en que Venezuela se encuentra desde fines de los años ochenta. Distingo aquí cuatro modelos de remediación de la lírica que hoy, aunque los mencione en el orden en que creo que aparecieron, coexisten como parte de un repertorio expresivo:

- Un modelo apegado a la plástica y fiel al espacio del libro.

- Un modelo en que el libro que ha asimilado a la plástica se complementa con la performance o la materialidad aurática de ediciones restringidas.

- Un modelo en que el libro acompaña otros medios como encrucijada de actos artísticos.

- Un modelo - el del Necromenaje - en que el libro no existe, transmitido todo componente lírico por otros medios, con primacía, pero no exclusividad, los digitales.

Los cuatro comparten la cualidad liminar de su expresión, que los diferencia de modos univocalizadores de entender la realidad. Ante la claridad de los dualismos que abundan en los discursos oficiales, esta poesía acude a umbrales, 
a espacios de fluidez: crítica del lenguaje, que es el punto de arranque para una crítica de lo real.

La noción de limen, que el antropólogo Victor Turner recuperó siguiendo las huellas, entre otros, de Arnold van Gennep, refiere, en principio, a transiciones iniciáticas entre categorías sociales estrictas (Van Gennep 18-21; Turner, The Forest 94-99; Turner, The Ritual 94-96). Los estudios sobre lo liminar han prosperado en la psicología, de allí los trabajos que debemos a Murray Stein acerca de sus aspectos míticorreligiosos, personificados por los griegos en Hermes, dios de la comunicación, los lenguajes secretos, guía de las almas en el mundo de las profundidades y, por tanto, en las fronteras entre lo personal y lo transpersonal (7-22). Quien más ha hecho para incorporar el concepto en los debates de arte contemporáneo ha sido Susan Broadhurst, en su libro Liminal Acts, donde acepta el estímulo de Turner, aunque enfatizando el limen "corpóreo, tecnológico y ctónico" (12; traducción del autor). El argumento principal de Broadhurst descansa en la importancia de las nuevas tecnologías para estimular procesos intersemióticos que propician "la heterogeneidad, lo experimental, lo marginado [...], la indeterminación, la fragmentación [así como] el colapso del contraste entre alta y baja cultura" (13).

El primer modelo venezolano de remediación de la lírica y su forma específica de umbral fiel todavía al libro podría ejemplificarse con poemarios de Blanca Strepponi posteriores a los saqueos de 1989 y a la cristalización del chavismo con el intento de golpe de Estado de 1992. En Las vacas (1995), la "mirada" de la autora, hasta entonces volcada a la ciudad o a hechos históricos, radicaliza sus introspecciones. En medio de una variedad de señales verbales - los versos-, pictóricas - Giorgione- y fotográficas - Robert Frank, Denis Thorpe, entre otros-, mientras el lector recompone un relato de infancia e identidad, la sensación de que no llegan a sus manos los códigos para descifrarlo perdura, sumergidos los poemas en las tinieblas del inconsciente y borrado el exteriorismo inicial de Strepponi, en deuda con el de los grupos caraqueños Tráfico y Guaire, de principios de los años ochenta, fascinados por la fenomenología de la modernidad. 


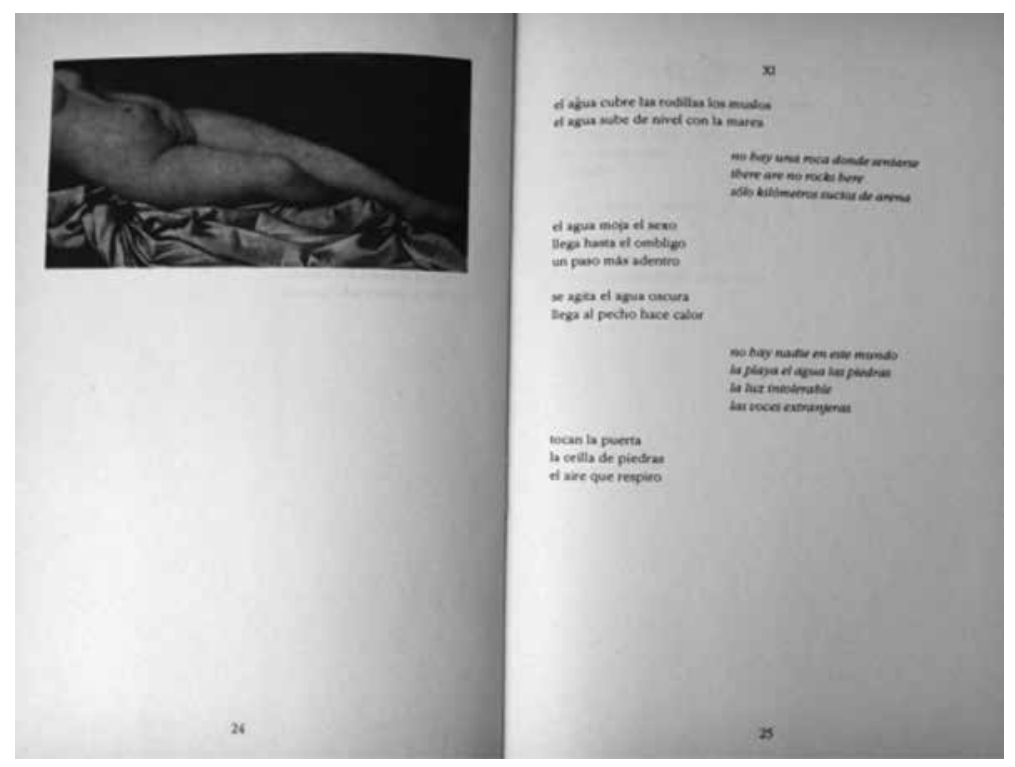

Strepponi, Las vacas

El siguiente libro de Strepponi, Balada de la revelación (2004), de tiraje limitado, casi una rareza, lleva a sus últimas consecuencias los descubrimientos de Las vacas, ya en transición hacia el segundo modelo de remediación, puesto que algunos pasajes se dieron a conocer antes de la impresión del volumen mediante una lectura pública sentida por la poeta como "experimental" (Strepponi, "Misiva" 9) en que los versos interactuaban con proyecciones de materiales visuales. ${ }^{3}$ No solo el diálogo con lo no verbal se desarrolla; lo hace, por igual, el mitema de un descensus ad inferos - recuérdese la cualidad ctónica de lo liminar según Stein y Broadhurst - legible psicológicamente, puesto que la autora dedica Balada "A Maritza Aguirre, mi exterapeuta". Si Las vacas concluía con la evocación de los abismos, el nuevo poemario empieza en ese dominio:

mis sueños hablan

todos los secretos

dicen las primeras cosas

todo lo que quiero saber

pero yo no entiendo

3 El acto se realizó el 27 de febrero de 1997, en el anfiteatro de Espacios Unión (Plaza Unión, Av. Universidad, Esq. El Chorro, Torre Grupo Unión, Edif. Anexo, mezzanina A, Caracas). 
se impacientan y se alejan

porque no entiendo

la lengua de los muertos

los rumores bajo el agua (s.p.)

El componente plástico de Balada es central. La visualidad exige, sin embargo, una lectura que permita entender que el código perseguido se mantendrá inasible en el bombardeo gráfico; pese a alguna ilustración literal, como la que acompaña a la sección II, donde los versos recorren diversas violencias de la historia venezolana, lo que vemos no se somete a articulaciones, consustanciado con el magma de lo presimbólico (Kristeva 17). El collage, en efecto, actúa como factor disgregador de signos que pudiésemos querer racionalizar y los deja al pairo en las aguas a las que aluden poemas, fotografías, dibujos. Retratos familiares de los Strepponi-Zingfain, artículos periodísticos, radiografías, un electrocardiograma de la autora de carne y hueso, fotos de vacas y la Venus dormida de Giorgione se turnan para crear un caos en el cual el lector deseoso de descubrir sistemas tiene que contentarse con sospecharlos. En las ocasiones en que lo visual da la impresión de revelar significados por su conjunción con el texto, como en las últimas páginas del segundo poema, la superposición oscurece los versos con un triunfo del absurdo:

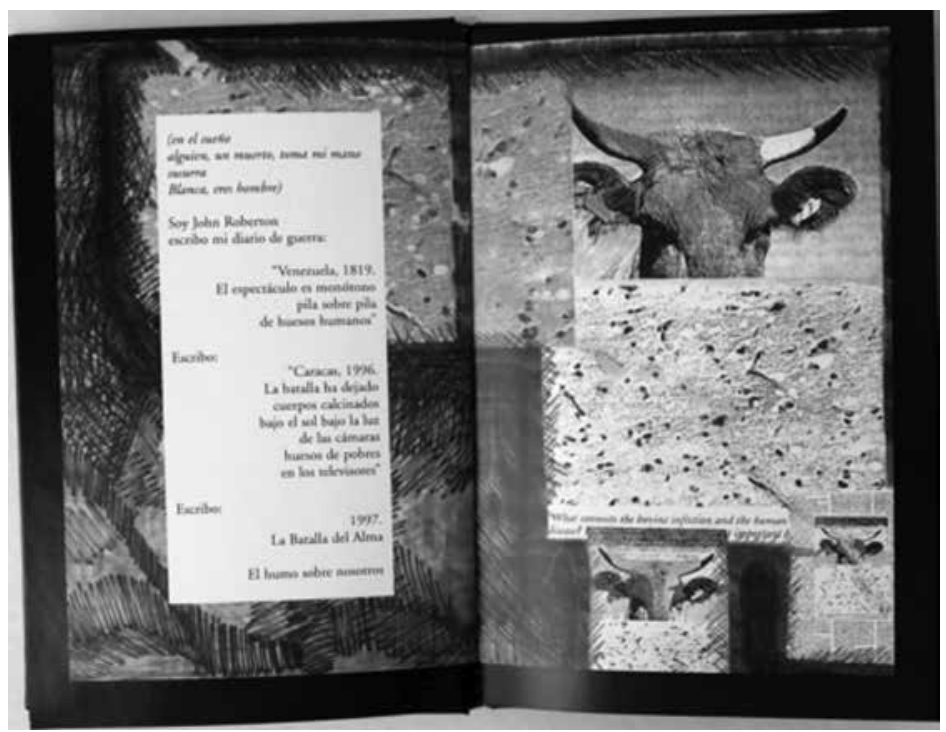

Strepponi, Balada de la revelación 1 
¿Qué relación podría haber entre la carrera poética de la autora, la Guerra de Independencia que presenció el médico británico John Roberton, la Caracas violenta de entre milenios y la epidemia de "vacas locas" de la prensa? Quizá la alusión al yin-yang en la última página insinúe el comercio de lo expresable y lo inexpresable:

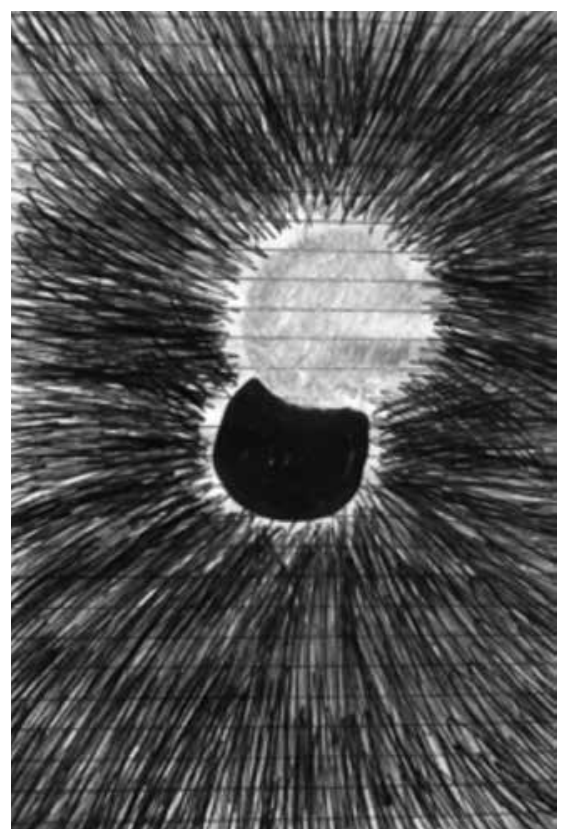

Strepponi, Balada de la revelación 2

Respecto al segundo modelo de remediación, con poemarios transformados en artefactos e indicios "performáticos", hallaremos más ejemplos en trabajos de Igor Barreto. Destacable es su empeño como poeta-editor en convertir el libro en espacio para contemplar la materialidad del lenguaje. Una entrevista con motivo de la publicación de un poemario en su editorial Sociedad de Amigos del Santo Sepulcro nos da pistas sobre su proyecto:

Stefanía Mosca: Todos los detalles (las ilustraciones, los editores, la ciudad y hasta el colofón) delatan cierta intencionalidad.

Igor Barreto: Yo pensé hasta en el formato.

SM: $\underset{i}{ }$ Pero existe esta Sociedad de Amigos del Santo Sepulcro?

IB: Mi familia, durante todas las Semanas Santas, se encargó de cuidar, pintar, arreglar, redecorar la imagen del Santo Sepulcro donada por mi tatarabuelo 
a la Iglesia de San Fernando [de Apure], cuando decidió abandonar la masonería. Había una conseja en el pueblo: se sabía que la masonería tenía en su seno una suerte de ley vengadora para los desertores que estuviesen tentados a revelar los secretos de la orden. A esas personas las seguía una "bola negra". Mi tatarabuelo, para evitar esa "bola negra" de la muerte, les regaló a los masones una estatua de Bolívar y el Santo Sepulcro a la Iglesia. Desde entonces, en mi familia, el Santo Sepulcro es un objeto de devoción enorme. (Librería Lugar Común s. p.)

Y los puentes entre arte y vida que erige Barreto se prolongan en otras actividades, como la publicidad en Facebook, que incluye la exhibición de tatuajes reales con el ex libris de su editorial y la interacción con los seguidores (Librería Lugar Común).

A los gérmenes de una performance paratextual que narrativiza la gestión del Barreto editor, hemos de sumar el componente visual de sus libros. Carreteras nocturnas (2010) es el que más expone el desagrado ante un sombrío entorno nacional asediado, por una parte, por la miseria y la abyección política - algún poema menciona al "triste coronel Chávez" (29) - y, por otra, por la oscuridad anímica - la extensa pieza final narra un viaje en autobús, de noche, a través de la geografía venezolana-. Las distonías de Carreteras nocturnas se vuelven materia trágica, lindante con la desesperación y un decir que, si bien se esfuerza en mantenerse fiel a lo racional o epigramático, acaba entregado a la escatología o lo grotesco. El traspaso entre lo gráfico y lo poético es vital. El diseño de Waleska Belisario con el predominio del negro nos prepara para la nocturnidad y los súbitos destellos viales que se avecinan en los versos, sentando un comportamiento de lectura en el que han de aceptarse estímulos múltiples. El volumen se divide en dos: una mitad, hasta la página 41, dedicada a los versos; la otra, desde la 42 hasta el final, a las fotografías de Ricardo Jiménez, colaborador consecuente de Barreto. Más allá de su función testimonial, las imágenes subrayan con su pertinaz atención al menoscabo de lugares e individuos, a la desolación o a la penumbra, la dimensión lóbrega de los versos. Pero enfatizan, además, la sensación de una realidad en ruinas, así como las conexiones con un presente sitiado por discursos heroicos, acaso los del "triste coronel", emparentados con un vacío tenebroso o tan enigmático y resistente a interpretaciones como el de cuadros de Chirico con espacios públicos ocupados por sombras o monumentos que no comparten su significado: 


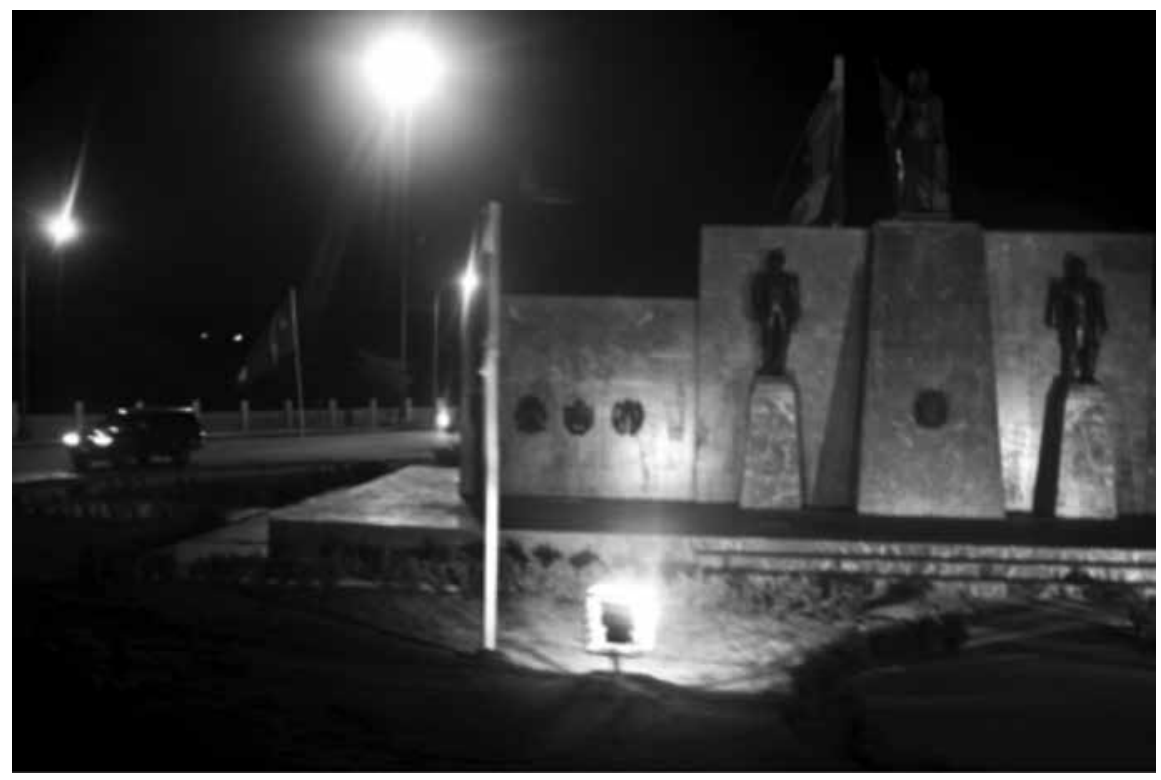

Foto: Ricardo fiménez

Un prototipo del tercer modelo de remediación lo ofrece el Willy McKey de Paisajeno (2011), libro que se convirtió en pieza de un denso tejido de acciones y lenguajes que giran en torno suyo. Importa recalcar que, tal como en el Necromenaje, El Techo de la Ballena vuelve a invocarse, aunque ahora con más ironía, pues se echa mano de la cultura $p o p$ estadounidense mediante un cómic intercalado y un interrogatorio al que Tonto somete al Lone Ranger para que reconstruya la historia poética venezolana (61), agregando el barroquismo de que el cómic homenajea a Roberto Bolaño, citado al calce (57-71).

Paisajeno, como muestra del tercer modelo de remediación, no se agota en el libro y acude a una performance editorial y extensiones digitales. La primera consistió en el anuncio en Internet, reforzado por noticias de las páginas culturales de los periódicos, de que el volumen había aparecido en una tirada de quinientos ejemplares y estaría a la venta no en librerías, sino en bares o restaurantes donde los interesados debían citarse con McKey por Twitter. Cada ejemplar estuvo firmado y sellado, con un video de la transacción subido a internet. La liminaridad de la inserción de mapas o cómics en el volumen impreso es solo un asomo de su hibridismo, puesto que desde la portadilla encontraremos la dirección de un blog donde accederemos a videos y audios que irán sometiéndose a écfrasis (http://bit.ly/paisajeno). El precio del libro lo determinaría el precio 
del barril de petróleo en el momento de la compra, lo que, desde luego, nos alerta sobre correspondencias con el horizonte político.

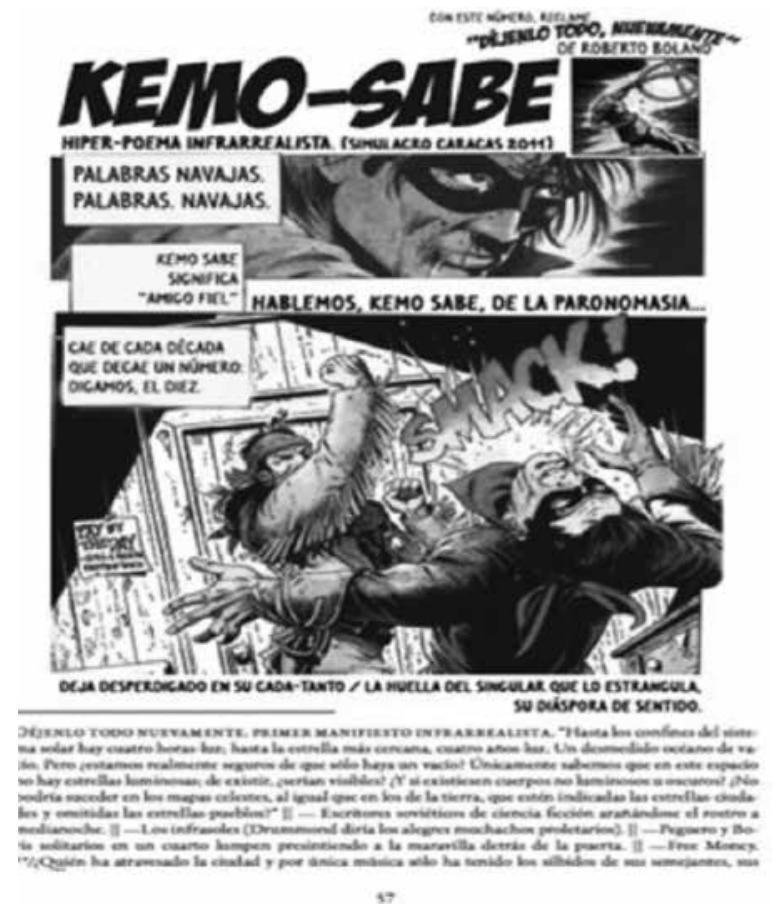

Willy McKey, Paisajeno

Una revisión cuidadosa de la historia venezolana que se entremezcla con la personal del hablante revela un talante crítico respecto del estentóreo patriotismo de los discursos estatales. La desacralización de la patria ensalzada por la oficialidad organiza el laberinto. Las profanaciones se consiguen con el movedizo neologismo del título - país ajeno; paisaje no (McKey, Paisajeno 20) - y con retazos flotantes de reflexión. Buena prueba la ofrece el juego con el referente once, repetido en poemas, materiales gráficos o videos. No cuesta percatarse de la imposibilidad de asignar acepciones a una palabra que parece reclamarlas. No basta con que captemos que se trata de un número español, una conjunción o un adverbio inglés y parte del nombre de una marca registrada (el Panqué Once-Once, que proustianamente conecta al personaje lírico con su infancia en la página 11 del libro). Más adelante, el once resurgirá, con la caída de un personaje desde un undécimo piso y lo que parece revelar el aura mágica de la palabra: "1980. Pude nacer once, ocho días antes de la licuefacción de la sangre de San Genaro" (14). 
Es decir: un indicador del nacimiento del sujeto poético vertebra este mundo de discursos. Avanzado Paisajeno, sin embargo, nos toparemos con otra interpretación. Al final del cómic y su repaso de la poesía venezolana del siglo XX, Tonto le pide a Kemo Sabe que hablen de lo "finisecular". Al no obtener respuesta, lo derriba de un puñetazo y dice, como única despedida, "ya llevamos once años de retraso" (73). Cuando reparamos en que Paisajeno se publica en 2011 el "régimen estético" se manifiesta anclando la escritura en su potencial político.

No es descabellado intuir que el "retraso" del que Tonto habla se produce en lo artístico y lo social. El tono vanguardista de poetas como McKey puede haberlo suscitado un ansia de renovación iniciática, que es, como Turner señalaba, liminar. Y el cambio, cuando entra en el terreno de las artes, de modo inevitable se asocia a un imperativo "moderno". Günter Berghaus sugiere que la transición de una cultura analógica a una digital indica la emergencia de una "segunda modernidad" que destruye el callejón sin salida de lo "posmoderno" con un estallido de experimentación como no lo ha habido desde la vanguardia (237). Berghaus, no obstante, dice que los nuevos "modernos" europeos o norteamericanos de fines del siglo XX e inicios del XXI resultan "escépticos del potencial revolucionario de sus discursos" (237; traducción del autor). La tónica del neoexperimentalismo venezolano es distinta: la "segunda modernidad" - ¿acaso todavía la primera en una cultura donde la modernidad ha sido "desigual" (Ramos 26)? - podría responder al fracaso de la modernidad "melancólica" del chavismo, que persiste, con la exhumación de un Padre enterrado, en un regreso a los orígenes decimonónicos de lo nacional.

Aquí la labor de McKey nos es útil, en particular, por sus contribuciones a definir el cuarto modelo de remediación como posibilidad expresiva en el campo cultural venezolano. El Necromenaje a la containerphilia de 2010 constituía un buen caso de esos experimentos sin libro, y en él se observan dos aspectos imprescindibles para respaldar mi tesis: uno, su voluntario arraigo en un ideal vanguardista, el que quería rescatar El Techo de la Ballena en los 1960 franqueando las barreras entre arte y vida con la dimensión "revolucionaria"; y el otro, el carácter político de tal proyecto, vertebrador incluso del quehacer estético. Santa al vacío (2014), una de las obras de McKey posteriores a Paisajeno, reafirma tanto la necesidad de acudir al modelo no libresco del Necromenaje como la efervescencia política de quien actúa legitimado por la autonomía literaria que le da la acumulación de capital simbólico gracias a sus experimentos previos. Santa al vacío es un rizoma creador explícitamente "deleuziano" al que accedemos en internet desde el blog de McKey. La proposición es, sin aspavientos, lúdica y acompañada de material gráfico: una estampita donde el poeta elabora 
una plegaria a "Nuestra Señora del Jabillo" debidamente encarnada por una modelo pelirroja (http://willymckey.com/santaalvacio/). Lo importante es que, tal como ocurre en $\mathcal{N}$ ecromenaje, esta liminaridad implica un esfuerzo de grupo, que incluye materiales audiovisuales en los que el poeta colabora con músicos - la "multinstrumentista mexicana" Carmen Ruiz, Ximena Borges y José Alejandro Delgado, cada uno de los cuales musicalizó los versos de McKey e interpretó las canciones-, con el respaldo de Ada Odreman y Andrea Cappiello en la creación del sitio. La descripción introductoria del autor nos da una idea de la hibridez del trabajo, desprendido de acciones anteriores en equipo:

Junto a la [gente de la] Organización Nelson Garrido [dedicada a la enseñanza de la fotografía], buscaba una oración imposible para cruzar Caracas. El contexto que enmarcó esa búsqueda fue una obsesión coyuntural: vimos que lo gringo y lo cubano hoy suenan más como acusaciones que como etiquetas, así que quisimos jugar a fundar la noción del frontier-yoruba-western. Lo pensamos para Santo, un proyecto poético todavía inacabado, pero fue una SANTA la que nos permitió probar la mezcla de los imaginarios de la santería y del Far West con la música del norte de México y la de Venezuela. (s. p.)

Los poemas-canciones de McKey, en efecto, se desplazan libremente por esos territorios, volviéndolos limen perpetuo con la misma fluidez de Paisajeno, y por eso no creo necesario someterlos a escrutinio más allá de lo que declara la voz prologal:

Tres poemas [uno con la tradición del patakí y el narcocorrido rebautizado necrocorrido en el Mercado de El Cementerio; otro que une a la oración y los Salmos 19 y 67 con la electrónica y el canto lírico; y uno que abraza cuatro décimas occidentalísimas con la ciudad grabándolas en un smart-phone] juntaron sonidos tan diversos como quienes tienen pensamientos distintos pero están unidos por la amistad, quienes se han tenido que ir al extranjero, quienes no se irán, e incluso extranjeros que han pasado por aquí y se llevaron algo de Caracas puesto en su manera de romper el silencio. (s.p.)

Pero sí es imprescindible subrayar que a estas alturas la liminaridad con la que viene experimentándose desde principios de la década de los noventa ha ido desarrollando una teoría propia y a McKey debemos su madurez: la heterogeneidad de códigos convocada bajo el hoy amplio techo de la poesía se describe a sí misma como reacción contra maniobras estatales de polarización — "lo gringo y lo cubano"-, exclusión — "quienes se han tenido que ir" - imposición de un discurso único — por ende, la mención de "romper el silencio"—. 
Otro dato para retratar la poética liminar que llega a su clímax con el cuarto modelo que representan obras como Santa al vacío lo hallamos en un comentario de la misma introducción:

Tenía otro pendiente creativo: el jabillo. Ese árbol de raíces feroces con las aceras, tronco espinoso, madera innoble y semillas que se diseminan después del estruendo de una explosión siempre me ha parecido una alegoría cruel pero efectiva de Caracas, un territorio dominado por la espina y por el cobijo, donde el cemento se rompe por lo crudo y arriba de nuestras cabezas resuenan explosiones con intenciones tan contradictorias como el espanto y la vida. (s. p.)

Si la doctrina gubernamental tiene en su núcleo binarismos inflexibles y si el pensamiento dualista elige alegoremas para formarse discursivamente, McKey, esforzándose en evidenciar el carácter tropológico de sus argumentos, readopta la alegoría con descaro: la proclama, casi podríamos decir, lo que de una vez desmiente toda ilusión de identidad con una realidad tangible o esencias que trasciendan la jurisdicción del lenguaje. Revelado el artificio, el deleuziano y caraqueño jabillo de esta poesía sin papel se transforma en una alegoría barroca como las entrevistas por Walter Benjamin (159-170) o las que luego fueron objeto de las meditaciones de Paul de Man (207), de ninguna manera las alegorías que siguen el patrón medieval o neoclásico — cuyos hábitos se observan en los discursos de Chávez-, las cuales, como señala Umberto Eco, exigían tablas autorizadas e indisputables de correspondencias en su ascenso hacia la verdad (161). Las oraciones de McKey son el resultado, hasta ahora el más complejo, de un esfuerzo colectivo desplegado en el campo cultural venezolano por ofrecer alternativas deconstructivas a la versión logocéntrica de la convivencia nacional que el Estado implanta desde 1999. Aun más memorable es que iniciativas como las de McKey y sus coautores no constituyen fenómenos solo estéticos, sino que tenemos pruebas suficientes de que han negociado también una condición ética, puesto que la performance autoral, la red paratextual que se ha tejido en torno a las obras, da claros signos de intervención en el horizonte comunitario.

\section{Obras citadas}

Barreto, Igor. Carreteras nocturnas. Fotografías de Ricardo Jiménez. San Fernando de Apure: Sociedad de Amigos del Santo Sepulcro/El Puente, 2010. Impreso.

Benjamin, Walter. The Origin of German Tragic Drama. Trad.

John Osborne. London: Verso, 1985. Impreso. 
Berghaus, Günter. Avant-garde Performance: Live Events and Electronics

Technologies. New York: Palgrave MacMillan, 2005. Impreso.

Bolter, Jay David y Richard Grusin. Remediation: Understanding

New Media. Cambridge: MIT UP, 2000. Impreso.

Bourdieu, Pierre. Les Règles de l'art: genèse et structure du champ littéraire. Paris: Seuil, 1992. Impreso.

Broadhurst, Susan. Liminal Acts: A Critical Overview of Contemporary Performance and Theory. London/New York: Cassell, 1999. Impreso.

Chávez Frías, Hugo. "Discurso ante la Soberana Asamblea Nacional Constituyente con motivo de la entrega del Proyecto de Constitución Bolivariana para la V República". Documentos fundamentales de la República Bolivariana de Venezuela. Caracas: Presidencia de la República, 2000. 7-15. Impreso.

Chávez Frías, Hugo. "Primera entrega". Las líneas de Chávez. Caracas: Ministerio del Poder Popular para la Comunicación y la Información, 2010. 5-7. Impreso.

De Man, Paul. Blindness and Insight. Mineappolis: University of Minnesota Press, 1983. Impreso.

Eco, Umberto. Semiotics and the Philosophy of Language. Blomington: Indiana University Press, 1984. Impreso.

Flores, María Antonieta. "La lentitud del cojo". Inti. Revista de Literaturas Hispánicas 75-76 (2014): 171-179. Impreso.

Jiménez, Ricardo. Fotografía sin título. Carreteras nocturnas de Igor Barreto. San Fernando de Apure: Sociedad de Amigos del Santo Sepulcro/El Puente, 2010. Impreso.

Kristeva, Julia. La révolution du langage poétique. Paris: Seuil, 1974. Impreso.

Librería Lugar Común. "El tatuaje de Igor Barreto". Facebook. com 10 de octubre de 2013. Web. 6 de julio de 2014.

Ludmer, Josefina. "Literaturas postautónomas". Ciberletras 17 (2007). Web. 1 de marzo de 2008.

McKey, Willy. "Carta electrónica" [correspondencia personal fechada el 12/8/2014 donde McKey, a petición mía, describe el Necromenaje a la containerphilia].

McKey, Willy. Descripciones públicas de la performance hechas por Mckey. Web. 1 de junio de 2014.

McKey, Willy. Paisajeno. Caracas: Ex Libris, 2011. Impreso.

McKey, Willy. Santa al vacío [Oratorio de Nuestra Señora del fabillo]. 4 de junio de 2014. Blog. 6 de junio de 2014.

McKey, Willy. willymckey.com/blog-2/. Blog. 
McKey, Willy, Santiago Acosta y Andrés González Camino. Necromenaje a la containerphilia [espectáculo poético]. Sala experimental La Caja, Centro Cultural Chacao, Caracas, 19 de noviembre de 2010.

Mosca, Stefania. "Los Amigos del Santo Sepulcro. Entrevista a Igor Barreto". Kalathos julio de 2001. Blog. 4 de septiembre de 2013.

Perloff, Marjorie. Radical Artifice: Writing Poetry in the Age of Media. Chicago: Chicago University Press, 1991. Impreso.

Pinardi, Sandra. "Disposiciones políticas de las artes visuales venezolanas contemporáneas: archivos de la violencia". El tránsito vacilante: miradas sobre la cultura venezolana contemporánea. Eds. Patricia Valladares-Ruiz, Patricia y Leonora Simonovis. Amsterdam/New York: Rodopi, 2013. 107-129. Impreso.

Rama, Ángel. Antología de El Techo de la Ballena. Caracas: Fundarte, 1987. Impreso.

Ramos, Julio. Desencuentros de la modernidad en América Latina: literatura y política en el siglo XIX. Santiago de Chile/San Juan de Puerto Rico: Cuarto Propio/Callejón, 2003. Impreso.

Rancière, Jacques. Le Partage du sensible: esthétique et politique. Paris: La Fabrique-éditions, 2000. Impreso.

Stein, Murray. In Midlife. Dallas: Spring Publications, 1983. Impreso. Strepponi, Blanca. Balada de la revelación. Caracas: Ediplus, 2004. Impreso.

Strepponi, Blanca. Las vacas. Caracas: Pequeña Venecia, 1995. Impreso.

Strepponi, Blanca. "Misiva a espacios unión". Los poetas en la intimidad. Caracas: Espacios Unión, 1997. 9. Impreso.

Torres, Ana Teresa. El oficio por dentro. Caracas: Alfa, 2012. Impreso.

Torres, Ana Teresa. La herencia de la tribu: del mito de la Independencia a la Revolución Bolivariana. Caracas: Alfa, 2009. Impreso.

Turner, Victor. The Forest of Symbols. Ithaca: Cornell University Press, 1967. Impreso.

Turner, Victor. The Ritual Process. Chicago: Adline, 1969. Impreso.

Van Gennep, Arnold. The Rites of Passage. Trads. Monika Vizedom y Gabrielle Caffee. Chicago: University of Chicago Press, 196o. Impreso.

Vargas Álvarez, Pedro Luis. "Postpolítica y postautonomía: desplazamientos hacia el mercado durante el llamado auge editorial venezolano". Voz y Escritura. Revista de Estudios Literarios 21 (2013): 35-54. Impreso.

Žižek, Slavoj. First as Tragedy, Then as Farce. London/New York: Verso, 2009. Impreso. 